\title{
Nesillerarası Etkileşim Kapsamında Yaşlı Yetişkinlerin Çocuk Kavramına İlişkin Yaklaşımları ve Metaforik Algıları
}

\author{
DOI: $10.26466 /$ opus. 908380
}

\begin{abstract}
$*$
Mehtap Pekesen*- Demet Çelik ${ }^{* *}$-Ayşe Sonay Türkmen***

* Akdeniz Üniversitesi Sağlık Hizmetleri Meslek Yüksekokulu Antalya/Türkiye E-Posta: mehtappekesen@gmail.com

ORCID: 0000-0003-2193-1675

** Karamanoğlu Mehmetbey Üniversitesi, Sağlık Bilimleri Fakültesi, Karaman/Türkiye

E-Posta: demet yan6@hotmail.com

ORCID: 0000-0002-4838-0714

*** Doç.Dr, Karamanoğlu Mehmetbey Üniversitesi, Sağlık Bilimleri Fakültesi, Karaman/Türkiye

E-Posta: asonaykurt@gmail.com

ORCID: $\underline{0000-0002-3716-3255}$

Öz

Bu araştırma nesiller arası etkileşim kapsamında yaşl yetişkinlerin "çocuk" kavramına ilişkin yaklaşımları ve metaforik algilarmı belirlemek amacı ile gerçekleştirilmiştir. Araştırmada nicel ve nitel araştırma yöntemlerinin birlikte yer aldığı iç içe karma araştırma yöntemi kullanılmıştır. Araştırma verileri araştırmacılar tarafindan oluşturulan tanitıcı bilgiler ve yarı yapılandırılmış görüşme formlan kullanilarak toplanmıştır ( $n=100)$. Verilerin analizinde Statistical Package for Social Sciences (SPSS) 21 paket programı ve içerik analizi tekniğinden yararlanılmıştır. Ayrıca metafor analizinde güvenirlik oluşturmak adına Miles ve Huberman (1994) güvenirlik formülü (Güvenirlik= Görüş Birliği/(Görüş Birliği + Görüş Ayrllı̆̆ ) kullanılmış ve kodlayıcılar arasındaki uyum oranı \%85.7 olarak tespit edilmiştir. Yaşll yetişkinlerin çocuk kavramına yönelik en sık kullandıkları metafor sırasıyla; hayat enerjisi ve mutluluk kaynağı olma, masum ve menfaatsiz olma, geleceğe dair umut kaynă̆̆ ve neslin devamımı sağlayıcı olma, şefkat ve sevgi dolu olma, bakıma ve korunmaya muhtaç olma, zorlayıcı ve yorucu olma, eğitilebilir olma, özgür olma, sorgulayıct-keşfedici olma ve sorumsuz olma kategorilerinden oluşmaktadı. Ayn zamanda yaşl yetişkinlerin torun sahibi olup-olmama değişkenine göre benzer ve farkl kavramsal kategorilerde metaforlara sahip olduklar belirlenmiştir.
\end{abstract}

Anahtar Kelimeler: Elli Yaş ve Üzeri, Yaşlı Yetişkin, Alğı, Nitel Çalışma, Metafor, Çocuk, Nesillerarası Etkileşim. 


\title{
Metaphoric Perceptions and Approaches to the Concept of Children in Old Adults in the Scope of Inter-Generation
}

\begin{abstract}
This research was carried out with the aim of determining the approaches and metaphorical perceptions of older adults regarding the concept of "child" within the scope of intergenerational interaction. Mixed research method, which includes both quantitative and qualitative research methods, was used in the study. Research data were collected using descriptive and semi-structured interview forms created by the researchers $(n=100)$. Statistical Package for Social Sciences (SPSS) 21 package program and content analysis technique were used in the analysis of the data. In addition, in the metaphor analysis, Miles and Huberman (1994) reliability formula (Reliability = Consensus / (Consensus + Disagreement) was used and the agreement rate between coders was found to be $85.7 \%$. The categories with the highest number of metaphors expressed by older adults about children are respectively; to be a source of life energy and happiness, being innocent and unexpected, being a source of hope for the future and ensuring the continuation of the generation, being affectionate and loving, needing care and protection, being challenging and tiring, being trainable, be free, interrogator-discoverer, and being irresponsible. At the same time, it was determined that older adults have similar and different conceptual categories according to the variable of having grandchildren or not.
\end{abstract}

Keywords: Fifty Years of Age and Older, Old Adult, Qualitative Study, Metaphor, Child,Intergenerational Interaction. 


\section{Giriş}

Artan yaşam süresi farklı nesillerin eş zamanlı olarak birlikte var olmaları ve yaşamaları koşulunu doğurmaktadır. Farklı nesillerin birlikte varoluşu, aynı zamanda birbirlerine karşı oluşan bazı ihtiyaçları da beraberinde getirmektedir. Nesiller arası dayanışma ve etkileşim hem yaşlı yetişkinlerin refahının hem de toplumların kendi varlıklarının sürdürülebilmesi açısından önem arz etmektedir. Ancak yaşlı yetişkinlerin, değişime uğrayan kültürel yapıyı kabul etme konusunda zorlanmaları, nesiller arasında görüş ve düşünce farklılıklarının oluşmasına sebep olabilmektedir. Bunun da ötesinde her neslin kendi döneminin şartlarına göre farklı olanaklarda yetişmesi, zaman içerisinde nesiller arası etkileşime ve birbirlerine yaklaşımlarına yansımaktadır (Yildirim, 2015).

Nesiller arası dayanışma ve etkileşimin ana unsuru aile birimidir. Çocuk toplumun bir üyesi olma yolunda içselleştirdiği değerleri ailenin rehberliğinde şekillendirmektedir. Yaşlı yetişkinlerin yaşamlarını anlamlı kılan unsurlardan biri çocukları ve torunlarıdır. Büyük ebeveynlerin başta torunları olmak üzere çocuklar ile kurdukları iletişimin temel unsurunu deneyim oluşturmaktadır. Çünkü bu yaş grubundaki kişiler oldukça deneyimlidir. Çocuklar için rol modeli olabilirler ve çocuklar onların tecrübelerine gereksinim duyabilirler (Horgan ve Fees, 2018).

Türk toplumunda torunla vakit geçirmek, bakımında rol oynamak aile büyükleri için önem taşımaktadır (Altan ve Tarhan, 2018). Ancak ailenin aktardığı değerler ve tutumlar her dönemin kendine has sosyokültürel ve tarihsel beklentileri çerçevesinde değişebilmektedir.

Yaşlı yetişkinlerin kendileri ile diğer kuşaklar arasındaki etkileşimi küçük çocukların gelişiminde etkisini göstermektedir. Özellikle 1-5 ve 6-12 yaş aralığındaki çocuklar için büyük ebeveynler ile beraber olmak en önemli sosyal ve eğitim ortamı sayılmaktadır. Çünkü ana-babaların (2.neslin) durumu göz önüne alındığında, tempoları hızlı, talepleri ve yaşanmamış deneyimleri fazla, daha çok üretme ve çalışma gibi sorumlulukları ile meşgul oldukları görülmektedir (Özmete, 2017). Günümüzde iş gücü piyasasının getirdiği süreç, aslında yaşlanan ve destek gereksinimi ortaya çıkan büyük ebeveynlerin torunlarının bakım sorumluluğunu almaya zorlamaktadır. Çocuğunu büyüten ve yetişkinliğe getiren büyük ebeveynin sorumluluğu torununun bakı- 
minı üstlenme ile yeniden şekillenmektedir (Suwanrada vd., 2018). Yaşlı yetişkinlerde torun ile oynamak, hatta bakımına yardımcı olmak konusunda çoğunlukla kendisine ihtiyaç olduğunu hissettiği ve yaşama bağlanması aç1sindan olumlu etkilerinin yaşandığı belirtilmektedir (Hacettepe Üniversitesi Geriatrik Bilimler Araştırma ve Uygulama Merkezi, 2020).

Ayrıca çocukların büyük ebeveynleri ile kurdukları olumlu iletişimin, onların sosyal, duygusal gelişimlerine pozitif katkı sağladığı bildirilmektedir (Yalçın, 2013). Yaşlı yetişkinler ve çocuk arasındaki olumlu etkileşim sonuçlarının bireysel yararlarının yanı sıra toplumu güçlendirme, sosyal hizmet ağlarını genişletme, insan kapitalinden en üst düzeyde yararlanma gibi olumlu katkılar sağladığı belirtilmektedir (Murphey vd., 2012). Uluslararası çalışmalarda büyük ebeveynlerin torunlarına bakmaktan mutluluk duydukları, onların gelişimine destek olmak istedikleri sonucuna ulaşılmıştır (Statham, 2011). İngiltere başta olmak üzere birçok ülkede torunlarına bakan büyük ebeveynler, başka çocuklara gönüllü bakmak için farklı isimler ile gruplar oluşturmuşlardır (New York is Ageless, 2021).

Son yirmi yılda, farklı söylemlerdeki metaforlar üzerine yapılan araştırmalarda yer alan kavramsal metafor teorisi, dil ve düşüncenin doğasına odaklanmaktadır. Bireyler için kavramlar, temel deneyimler ile şekillenir ve bu kavramlar dilsel kalıplar ile ifade edilmektedir (Goschler, 2007). Bir fenomen olarak metafor, hem kavramsal eşleştirmeleri hem de bireysel dilsel ifadeleri içermektedir. Metaforlar sadece belirli bir kelime veya ifadeyi temsil etmez. Metafor sadece bir dil meselesi değil, aynı zamanda düşünce ve akıl meselesidir. Metafor, bireylerin kendi dünyalarını tanımlamaları, yorumlamaları ve yapılandırmalarına yönelik güçlü bir zihinsel haritalama ve modelleme mekanizmasına dikkat çekmektedir. "Aşk bir yolculuktur" olarak kavramsallaşan bir metafor haritalamasında aşkın bir yolculuk olarak nasıl kavramsallaştırıldığı anlatılmaktadır. Metaforlar düşüncelerimize, hareketlerimize, diğer insanlarla ilişki kurma biçimimize etki etmektedir (Lakoff, 1992).

Metafor kullanımı, genel olarak bireylerin dünyayı algılayışını yapılandıran düşünme ve görme biçimi anlamına gelmektedir. Metafor, dinleyici veya okuyucuda bilişsel sürecin başlamasını sağlamaktadır. Bilişsel ve duyuşsal süreçlerin birbirleri ile etkileşime girmesi, metaforun birey üzerindeki etkisinin gücüne işaret etmektedir. Metaforlar, genel olarak söylemek istediğimiz şeyleri daha az sözcük ile daha vurgulu biçimde ifade etmemizi sağlamaktadır. Metaforlar bireyi yaratıcı düşünmeye, hayal etmeye, kendi yaşantısı 
içinde yorumlamaya yönlendirmektedir. Dolayısıyla, bireylerin yaşantılarını, düşünce ve duygularını tanımlamalarında metaforlardan yararlanmaları kaçınılmazdır (Aladağ ve Kuzgun, 2015). Çünkü metaforlar, kavramların daha kolay anlaşılması ve yorumlanmasına hizmet etmektedir. Metafor yöntemi ile analiz edilen kavramın bireyler tarafından nasıl algılandığı, hangi anahtar kelimeler ile tanımlandığı gibi derinlemesine yoğunlaşma yapılarak konuya açıklık getirmek amaçlanmaktadır (Kasapoğlu, 2016).

$\mathrm{Bu}$ araştırma, nesiller arası etkileşim kapsamında yaşlı yetişkinlerin "çocuk" kavramına ilişkin yaklaşımlanı ve metaforik algılarını ortaya çıkarmak amacı ile gerçekleştirilmiştir.

Ülkemizde nesiller arası bağların güçlenmesi, dayanışma ve birliğinin korunmasına yönelik torun -büyük ebeveynlerin ilişkisini inceleyen yeterli sayıda araştırma bulunmamaktadır. Halbuki yaşam süresinin uzaması ve artan yaşlı nüfus oranları, nesiller arası dayanışma ve etkileşimin güçlendirilmesini gerektirmektedir (Türkiye İstatistik Kurumu (TÜİK, 2019). Bu bakımdan nesiller arası dayanısma ve etkileşim kapsamında nesillerin birbirini algılama biçimleri de önem arz etmektedir.

Son yıllarda nesiller arası dayanışma ile ilgili çalışmaların literatürde sıklıkla yer almasına karşın yaşlı yetişkinlerin çocuklara yönelik yaklaşım ve algılamalarını belirleyen çalışmaya rastlanılmamıştır. Yaşlı yetişkinlerin çocuk kavramına ilişkin yaklaşımlarının ve algılarının, davranışlarını da etkilediği dolayısıyla nesiller arası etkileşimde rol oynadığı düşünülmektedir. Yaşlı yetişkinler ve çocuk arasındaki olumlu etkileşim toplumu güçlendirme, sosyal refah ve barış için önem arz etmektedir. Bu doğrultuda nesiller arası dayanışma ve etkileşimde, yaşlı yetişkinlerin çocuk algısının, önemli bir değişken olduğu ve belirlenmesinin literatüre katkı sağlayacağı düşünülmektedir. Araştırmada bu amaç çerçevesinde aşağıdaki sorulara cevap aranmıştır:

Araştırma kapsamında şu sorulara cevap aranmıştır:

1. Yaşlı yetişkinlerin demografik/tantıcı özellikleri nelerdir?

2. Yaşlı yetişkinlerin çocukluk dönemleri ile ilgili deneyimleri nelerdir?

3. Yaşlı yetişkinlerin çocuk ile iletişim deneyimleri nelerdir?

4. Yaşlı yetişkinlerin torun sahibi olup olmama değişkenine göre çocuk kavramına yönelik metaforik algıları nelerdir? 


\section{Yöntem}

\section{Araştırma Modeli}

Araştırmada nicel ve nitel araştırma yöntemlerinin birlikte kullanıldığ karma araştırma yöntemlerinden iç içe karma araştırma yöntemi kullanılmıştır.

\section{Araştırma Grubu}

Araştırmanın çalışma grubunu, 1 Ekim 2018 -1 Nisan 2019 tarihleri arasında Karaman İl Merkezinde gönüllülük esasına dayalı, rastgele seçilen araştırmaya dahil edilme kriterlerine uygun kişiler oluşturmaktadır. Katılımcılar ile yüz yüze derinlemesine görüşme yapıldığı için katılımcı sayısı verilerin tekrarlanma durumuna göre belirlenmiştir. Araştırmacı bilgileri veya delilleri bulana kadar örneklemeye devam eder. Verilerde doyum noktasına ulaşınca yani veriler tekrarlandığ1 zaman veri toplama işlemine son verilir (Erdoğan, 2015). Veri doygunluğuna 100 kişide ulaşıldığı için araştırmacılar tarafından veri toplama işlemi sonlandırılmış ve araştırma 100 kişi ile gerçekleşmiştir.

\section{Araştırmaya Dahil Edilme Kriterleri}

- Araştırmanın yapıldığı tarihler arasında 50 yaş ve üzeri olmak

- Araştırmaya katılmayı kabul etmek

- Bilgi formunu tam doldurmak

- Herhangi bir mental ve konuşma problemine sahip olmamak

\section{Araştırmaya Dahil Edilmeme Kriterleri}

- Araştırmanın yapıldığı tarihler arasında 50 yaş ve üzeri olmamak

- Araştırmaya katılmayı kabul etmemek

- Bilgi formunu tam doldurmamak

- Herhangi bir mental ve konuşma problemine sahip olmak 


\section{Veri Toplama Araçları}

Literatür doğrultusunda araştırmacılar tarafından hazırlanan bilgi formu ve yarı yapılandırılmış görüşme soruları 28 sorudan ve 4 bölümden oluşmaktadır. Araştırmanın yarı yapılandırılmış soruları araştırmacının çalışma içindeki önyargılarını azaltmak ve görüşme sorularının güvenilirliğini kontrol etmek için bir saha testine tabii tutulmuştur. Saha testi sonucuna göre, gerekli düzenleme ve değişiklik yapılarak sorulara son şekli verilmiştir. Saha testi uygulaması araştırmaya ve analizlere dahil edilmemiştir. Birinci bölümde katılımcların demografik/tanıtıcı özellikleri (yaş, cinsiyet, medeni durumu, kronik hastalık varlığı vb.), ikinci bölümde çocukluk dönemi deneyimleri, üçüncü bölümde çocuk ile iletişimi (torun veya çevresinde bulunan çocuk(lar) ile etkileşim durumu) ve dördüncü bölümde torun sahibi olup-olmama değişkenine göre çocuk kavramına ilişkin metaforik algıları ile ilgili sorular bulunmaktadır.

Araştırmanın bu bölümünde katılımcıların "çocuk" kavramına ilişkin algıları metaforlar yoluyla elde edilmiştir. Bu bağlamda yaşlı yetişkinlerin “Çocuk .... gibidir; çünkü ......" ifadesini tamamlamaları istenmiştir.

\section{Verilerin Toplanması}

Katılımcılara araştırma konusu ve görüşmelerin yazılı ve ses kaydına alınacağı ile ilgili ön bilgi verilmiş olup sözlü onamları alınmıştır. Araştırma verilerini toplamak için Karaman'ın kişi sayısının en yoğun olduğu merkez alanları (İsmet Paşa Caddesi, Aktekke Meydanı) seçilmiştir. Veriler aynı araştırmacı tarafından yüz yüze görüşme yöntemi ile yaklaşık 30 dakika (25-30dk) süre içerisinde toplanmıştır. Görüşmeler, ses kayıt etme özelliği olan cep telefonuna kaydedilmiştir ve eş zamanlı notlar alınmıştır. Katılımcıların cevaplarını etkileyebilecek yönlendirmelerden kaçınılmıştır.

\section{Verilerin Analizi}

Araştırmanın nicel veri toplama bilgi formundan elde edilen veriler Statistical Package for the Social Sciences (SPSS)-21.00 paket programı kullanılarak değerlendirilmiştir. Verilerin değerlendirilmesinde tanımlayıc istatistikler kul- 
lanılmıştır. Araştırmanın nitel verilerini kapsayan görüşme sorularının çözümünde ise tüme varımsal içerik analizi tekniğinden yararlanılmıştır. İçerik analizi eldeki kayıtların anlaşılması ve karşılaştırılması için kullanılan bir yöntemdir. İçerik analizi tekniklerinden olan kategori analizi mesajların birbirleri ile ilgileri bakımından kategoriler halinde bir araya getirilmesi ve kelimelerin anlamlarına odaklanılmasıdır (Arıkan, 2011).

Verilerin analizinde yazıya dökülen transkriptlerin satır satır okuma tekniği ile birkaç kez okunmasından sonra; 1) verilerin tematik kodlaması, 2) s1nuflandırılması ve temaların bulunması, 3) temaların organize edilmesi ve 4) bulguların yorumlanması yapılmıştır. Benzer kodlardan kategoriler ve temalar oluşturulmuştur. Tematik kodlamada üç araştırmacı aynı veri seti üzerinde bağımsız bir şekilde çalışmışlardır. Araştırmacılar kodlamaların üzerinde uzlaşı olup olmadığını incelemişler ve içerik benzerliğini dikkate alarak sınıflandırma ve temalara ulaşılmıştır. Ayrıca temaların güvenilirliğini sağlamak için transkriptlerin çift kodlaması bağımsız bir araştırmacı tarafından yapılmıştır. Katılımcıların isimlerine yer verilmezken, kullanılmak üzere transkriptler sırasında kodlar verilmiştir (E1.....E100)

Çocuk kavramına ilişkin metaforların analizi üç aşamada gerçekleştirilmiştir:

İlk olarak katılımcıların geliştirdiği metaforlar listelenmiştir. Herhangi bir metafor imgesi içermeyen ya da metafora ilişkin geçerli bir gerekçe sunulmamış (11 katılımc1) metaforlar uzman görüşü doğrultusunda elenmiştir. Geçerli kabul edilen 89 katılımcının ürettiği 60 metafor alfabetik sıraya göre listelenmiştir. Aynı metafora üç ya da daha fazla sayıda katılımcı tarafından yer verilen başat metafor imgeleri belirlenmiştir.

İkinci aşamada, metaforların özellikleri ve açıklamaları dikkate alınarak "çocuk" kavramına ilişkin kategoriler oluşturulmuştur. Üçüncü aşamada çocuk kavramına ilişkin oluşturan kategoriler ve yaşlı yetişkinlerin bu kategorilere dağılımı uzman görüşüne sunulmuştur. Bu aşamada gerekli görülen bazı metaforların kavramsal kategorileri değiştirilmiştir. Uzman görüşü ve araştırmacılar tarafından oluşturulan kategorilerin karşlaştıılması nitel verilerin analizinde sıklıkla kullanılan Miles ve Huberman (1994) güvenirlik formülü (Güvenirlik=Görüş Birliği/(Görüş Birliği+Görüş Ayrıllğı)X100 kullanılarak hesaplanmıştır. Hesaplamalara göre çocuk kavramına ilişkin araştırmacıların uyum oranı güvenirliliği: $(60 /(60+10) X 100)=\% 85,7$ olarak bulun- 
muştur. Güvenirlik formülüne göre analizin \% 70'in üzerinde çlkması güvenilir olduğu anlamına gelmektedir (Miles ve Huberman, 1994). Araştırmada kodlayıclar arası uyumun yeterli olduğu söylenebilir. Ayrıca 60 metaforu ve 10 kategoriyi temsil eden katılımcı sayısı (n) ve yüzdesi (\%) hesaplanmıştır.

\section{Araştırmanın Etik Boyutu}

Araştırmanın yapılabilmesi için Karamanoğlu Mehmetbey Üniversitesi Sağlık Bilimleri Fakültesi Girişimsel Olmayan Etik Kurulu'ndan (09-2018/24) yazılı izin alınmıştır. Ayrıca, veri toplama sürecinde katılımcılara araştırma ile ilgili ön bilgi verilmiş olup sözlü onamları alınmıştır.

\section{Araştırmanın Sınırlılıkları}

Araştırmanın sınırlılıkları olarak araştırma kapsamında sınırlı sayıda 50 yaş ve üzeri bireyler ile görüşülmesi, katılımcıların torun sahibi olup-olmama değişkeninin yorumlanmasında eşit sayıda olmaması ve nitel bir araştırma olması nedeniyle sonuçların genelleyememe özelliği sayılabilir.

\section{Bulgular}

Bulgular kısmı araştırma soruları doğrultusunda beş bölümde ele alınmıştır.

Yaşlı yetişkinlerin demografik özellikleri: Yaşlı yetişkinlerin \%57' si 50-59 yaş grubunda olup \%54' ü kadın olarak belirlenmiştir. Katılımcıların çoğunluğu kronik bir hastalığının olduğunu (\%80), il merkezinde ikamet ettiğini (\%70), en az bir tane torununun olduğunu $(\% 87,3)$ beyan etmiştir. Torunları olan yaşlı yetişkinlerin $\% 44,9^{\prime}$ unun torunları ile vakit geçirmediği saptanmıştır. 
Tablo 1. Yaşlı yetişkinlerin demografik özelliklerine göre dağılımlan (n=100)

\begin{tabular}{|c|c|c|}
\hline Demografik özellikler & Sayı (n) & Yüzde (\%) \\
\hline \multicolumn{3}{|l|}{ Yaş } \\
\hline $50-59$ & 57 & 57 \\
\hline $60-71$ & 43 & 43 \\
\hline \multicolumn{3}{|l|}{ Cinsiyet } \\
\hline Kadın & 54 & 54 \\
\hline Erkek & 46 & 46 \\
\hline \multicolumn{3}{|l|}{ İkamet } \\
\hline İl merkez & 70 & 70 \\
\hline İlçe/köy & 30 & 30 \\
\hline \multicolumn{3}{|l|}{ Ekonomi } \\
\hline Gelirim giderimden az & 33 & 33 \\
\hline Gelirim giderime eşit & 47 & 47 \\
\hline Gelirim giderimden fazla & 20 & 20 \\
\hline \multicolumn{3}{|l|}{ Eğitim } \\
\hline İlkokul & 58 & 58 \\
\hline Ortaokul ve Lise & 42 & 42 \\
\hline \multicolumn{3}{|l|}{ Medeni Durum } \\
\hline Evli & 74 & 74 \\
\hline Bekar & 26 & 26 \\
\hline \multicolumn{3}{|l|}{ Kronik hastalık durumu } \\
\hline Evet & 82 & 82 \\
\hline Hayır & 18 & 18 \\
\hline \multicolumn{3}{|c|}{ Toruna sahip olma durumu } \\
\hline Evet & 87 & 87 \\
\hline Hayır & 13 & 13 \\
\hline \multicolumn{3}{|l|}{ Torun sayısı } \\
\hline 0 & 13 & 13 \\
\hline 1 & 24 & 24 \\
\hline 2 & 22 & 22 \\
\hline 3 ve üzeri & 41 & 41 \\
\hline \multicolumn{3}{|c|}{ Torunlanı ile vakit geçirme durumları $(n=87)$} \\
\hline Evet & 48 & 55,1 \\
\hline Hayır & 39 & 44,9 \\
\hline
\end{tabular}

Yaşlı yetişkinlerin çocukluk dönemi deneyimleri: Katılımcılar kendi çocukluk dönemi deneyimlerini tanımlarken; keyifli ve mutlu, zorluklar içerisinde ve çalışarak geçirdikleri şeklinde ifadeler kullanmıştır. Bunun yanı sıra katılımcılar arasında olumsuz koşullara rağmen çocukluk dönemini mutlu hatırlayanlar da yer almaktadır. Yaşlı yetişkinlerin çocukluk dönemi deneyimlerine ilişkin görüşlerine göre belirlenen temalara Tablo 2'de yer verilmiştir. 
Tablo 2. Yaşlı yetişkinlerin çocukluk dönemi deneyimlerine ilişkin görüşleri

\begin{tabular}{lll}
\hline Temalar & Sayı (n) & Oran (\%) \\
\hline Keyifli ve Mutlu Hatırlanan Çocukluk Deneyimi & 40 & 40 \\
Zorluklar ile Mücadele Şeklinde Hatırlanan Çocukluk Deneyimi & 23 & 23 \\
Çocuk Yaşta Çalışma Sorumluluğu ile Hatırlanan Çocukluk Deneyimi & 29 & 29 \\
Olumsuz Şartlara Rağmen Mutlu Hatırlanan Çocukluk Deneyimi & 8 & 8 \\
\hline
\end{tabular}

Katılımcların \%40'1 ( $\mathrm{n}=40)$ çocuk dönemini keyifli ve mutlu geçirdiğini ifade etmiştir. Katılımclların çoğunluğu çocukluğunu iyi geçirme nedeni olarak oyun oynayabilmelerini işaret etmiştir.

Katılımclların \%23'ü çocukluk döneminin zorluklar içerisinde geçtiğini bildirmiştir. Katılımclar çocukluk dönemi zorlukları olarak sevgisiz büyüme, ebeveyn ayrilıkları ve ebeveyn kaybı tanımlamalarına yer vermiştir. Bir katılımc1 (E2); "Ah çocuğum sevgi görmedik. Çocukluğum babaanne dede yanında geçti. Anne baba sevgisi yoktu. Ayda yılda bir görüşürdük. İş çoktu..." şeklinde ifade etmiştir. Annesizlikten kaynaklı çocukluğunun zor olduğunu düşünen katılımcılar da vardı. Bir katılımcı (E32) yaşadıklarını; "Çocukluğumu çok kötü geçirdim. Annesiz büyüdüm. Babam çok huzursuzdu... " cümleleri ile açıklamıştır. Bir katılımcı (E58) yaşadıklarını; "... 7 yaşında anne babam ayrıldı ve ben okula gidiyordum. Hiç kimsenin işine karışmadım, dışlandım çocukluğum hep yalnız geçti" şeklinde açıklamıştır.

Katılımcların \%29'ü çocukluğunu çalışarak geçirdiğini ifade etmiştir. Özellikle köyde yaşayan ailesi çiftçilik yapan yaşlı yetişkinler çocukluk dönemlerini genelde tarlada çalışarak ya da koyun güderek geçirdiğini belirtmiştir. Katılımcılar yoksulluk, imkansızlık ve okuyamamaktan dolayı yaşadığı üzüntülerini ifade etmiştir. Bir katılımcı (E97) duygularını; "Hayata erken atıldım. Çocukluk nedir bilmedim. Hep imrenirim annesi ve babası ile vakit geçirebilen çocuklara. Çünkü ben onları çok erken kaybettim. Öksüz ve yetim olmak çok zor. Allah hiçbir çocuğa böyle bir acı yaşatmasın..." sözleri ile ifade etmiştir.

Buna karşın bazı katılımcılar ise çocuklu dönemlerinde yaşanılan tüm olumsuz koşullara rağmen çocukluk dönemlerini yine de mutlu hatırladıklarını belirtmiştir. Bir katılımcı (E100) duygularını; "Çok rezil geçti. Yokluk içindeydi ama o bile güzeldi. Çamurla oynamak dişarıda oynamak çok güzeldi" şeklinde ifade etmiştir. Bir başka katılımcı (E89) ise "Biz çok kardeştik. Annem çalışmaktan bizimle ilgilenemezdi. Ama biz kardeşlerimle bezden bebekler yapardik hayvanlarla oynardık ağaçlara çıkardık her şeye rağmen güzeldi... " şeklinde ifade etmiştir. 
Yaşlı yetişkinlerin çocuk ile iletişim deneyimleri: Katılımcllardan çevrelerindeki ya da tanıdığı çocukları düşünmeleri ve iletişim kurabilme durumlarını değerlendirmesi istenmiştir. Katılımcıların çocuklar ile iletişim kurmasını etkileyen kolaylaştırıcı ve engelleyici unsurlar katılımcıların yanıtlarına göre yaşlı yetişkin ve/veya çocuğa ait özellikler başlıkları altında değerlendirilmiştir (Tablo 3).

Tablo 3. Katılımcıların çocuklar ile iletişim kurmasını etkileyen unsurlar*

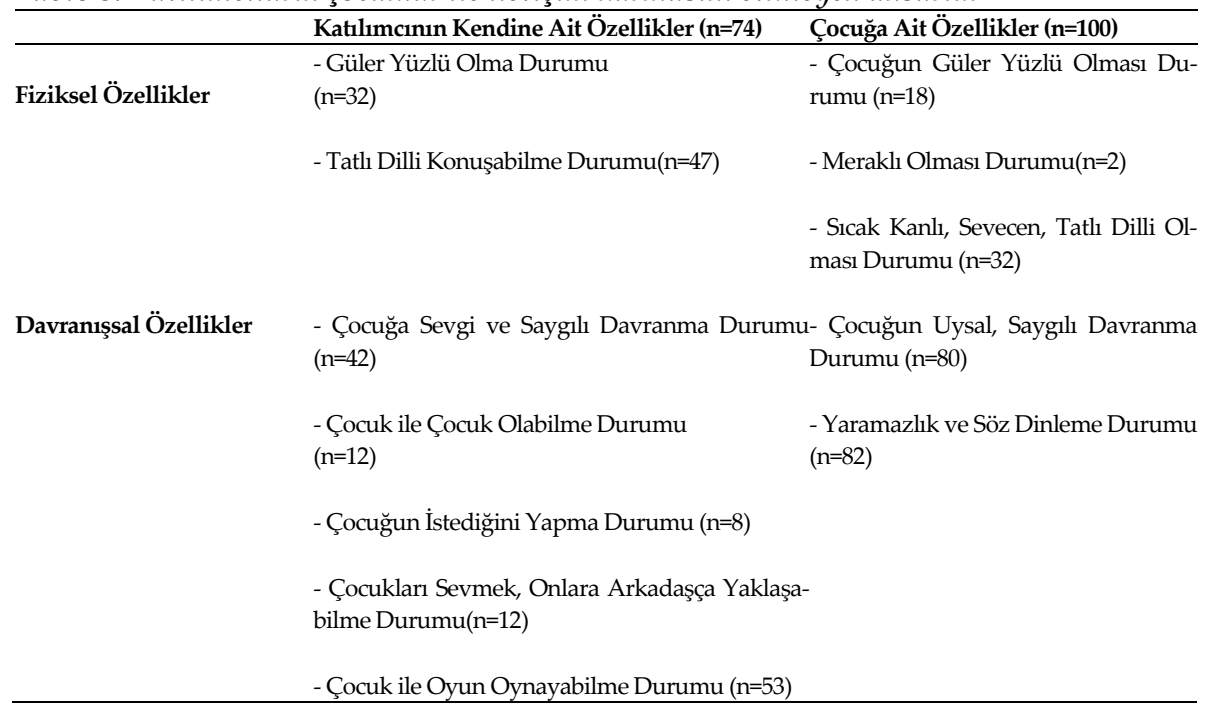

${ }^{*}$ Aynı katılımcılar birden fazla görüş belirtmiş ve tanımlama yapmıştır.

Katılımcların tamamı çocuk ile iletişimi kolaylaştıran ya da engelleyen etkenlerin yaşlı yetişkin ve/veya çocuğa ait özelliklerden oluştuğunu ifade etmişlerdir. İletişim sırasında tarafların fiziksel ve davranışsal özelliklerinin kolaylaştırıcı ya da engelleyici olarak rol oynadığı belirlenmiştir.

Çocuklara karşı tatlı dil ile konuşmanın etkinliğini; "Bir tebessüm, tath dil, çocuklara karşı anı yakalamak" şeklinde ifade etmiştir (E60). Çocuk ile çocuk olabilmenin önemini bir katılımcı şu sözlerle açıklamıştır; "Çocuğa çocuk gibi davranırsan onunla çok güzel iletişim kurabilirsin hele birde çocuk güler yüzlü ise oldukça güzel iletişim kurulur" (E79). Çocuk ile iletişimde çocuğun fiziksel özelliklerinin önemli olduğunu belirten bir katılımcı çocuğun sevecenliğine; "Yani çocuk sevecen olursa işte o zaman iyi bir iletişim kurulabilir" sözleri ile vurgu 
yapmıştır (E78). Çocuk ile iletişimde çocuğun saygılı davranmasının şart olduğunu belirten bir katılımcı ise; "Saygll olmaları, hürmet etmeleri. Başka da bir şey gelmez aklıma" şeklinde açıklamıştır (E70).

Yaşlı yetişkinlerin "çocuk" kavramına ilişkin metaforları: Bu araştırmada elde edilen bulgulara göre, çocuk kavramına ilişkin olarak 89 katılımcı tarafından toplam 60 adet geçerli metafor üretilmiştir. Bu metaforlardan 7 tanesi sadece bir katılımcı tarafından ifade edilmiştir. Geriye kalan 53 metaforu temsil eden katılımcı sayısı ise 2 ile 4 arasında değişmektedir. Birden fazla katılımcı tarafından ifade edilen metaforlar sırasıyla bayram şekeri $(\mathrm{n}=3)$, bahar mevsimi $(\mathrm{n}=4)$, terapi $(\mathrm{n}=2)$, melek $(\mathrm{n}=6)$, temiz $\operatorname{kalp}(\mathrm{n}=3)$, fidan $(\mathrm{n}=3)$, tohum $(n=3)$, bereketli toprak $(n=2)$, maya $(n=2)$, can yoldaşı $(n=2)$, tutunacak dal $(n=2)$, sevgi çiçeği $(n=2)$, çiçek $(n=3)$, yavru( $(n=2)$, bitki fidesi $(n=2)$, gürültü $(\mathrm{n}=2)$, işlenmemiş maden $(\mathrm{n}=2)$, hamur $(\mathrm{n}=2)$, kuş $(\mathrm{n}=2)$ metaforlarıdır. Kattlımcılar tarafından oluşturulan çocuk algısı metaforları ve bu metaforlara yönelik olarak belirlenen kavramsal kategoriler Tablo 4' de yer almaktadır.

Tablo 4 incelendiğinde en çok metaforun hayat enerjisi ve mutluluk kaynağı olma (\%18,3) kategorisinde oluştuğu, onu masum ve menfaatsiz olma $(\% 13,3)$, geleceğe dair umut kaynağı ve neslin devamını sağlayıcı olma $(\% 11,7)$, şefkat ve sevgi dolu olma $(\% 11,7)$, bakıma ve korunmaya muhtaç olma (\%10), zorlayıcı ve yorucu olma (\%10), eğitilebilir olma (\%8,3), özgür olma $(\% 6,7)$ kategorilerinin izlediği görülmektedir. Bu kategorileri sorgulayıc1, keşfedici olma (5) ve sorumsuz olma (5) kategorileri izlemiştir. Bu kategorilere ait metaforlar ve bu metaforlara ait katılımcı yorumları şöyledir: 
Nesillerarası Etkileşim Kapsamında Yaşlı Yetişkinlerin Çocuk Kavramına İlişkin Yaklaşımları ve Metaforik Algıları

Tablo 4. Yaşlı yetişkinlerin çocuk kavramına ilişkin metaforlarn ve kategorilere göre dă̆ılimi**

\begin{tabular}{|c|c|c|c|c|c|c|c|c|c|}
\hline \multirow[t]{2}{*}{ Kategoriler } & \multirow[t]{2}{*}{ Metaforlar } & \multicolumn{2}{|c|}{ Metafor } & \multicolumn{2}{|c|}{$\begin{array}{l}\text { Torunu Olan } \\
\text { Katılımci }\end{array}$} & \multicolumn{2}{|c|}{$\begin{array}{l}\text { Torunu Ol- } \\
\text { mayan Kat1- } \\
\text { lımcı }\end{array}$} & \multicolumn{2}{|c|}{ Toplam } \\
\hline & & $\bar{n}$ & $\%$ & $\mathbf{n}$ & $\%$ & $\mathbf{n}$ & $\%$ & $\mathbf{n}$ & $\%$ \\
\hline $\begin{array}{l}\text { Hayat Enerjisi ve } \\
\text { Mutluluk Kaynağı }\end{array}$ & $\begin{array}{l}\text { Bayram Şekeri, Çikolata, Gökku- } \\
\text { şağı, Bahar Mevsimi, Mutluluk İk- }\end{array}$ & & & & & & & & \\
\hline Olma & $\begin{array}{l}\text { siri, Kanarya, Mızıka, Neşeli Müzik, } \\
\text { Terapi, İkramiye, Aş Evi }\end{array}$ & 11 & 18,3 & 12 & 18,8 & 5 & 20 & 17 & 19,1 \\
\hline $\begin{array}{l}\text { Masum ve Menfa- } \\
\text { atsiz Olma }\end{array}$ & $\begin{array}{l}\text { Su, Akarsu, Temiz Sayfa, Melek, } \\
\text { Başlangıç Noktası, Ücretsiz Konser, } \\
\text { Temiz Kalp, Güzel Ruh }\end{array}$ & 8 & 13,3 & 9 & 14 & 6 & 24 & 15 & 16,9 \\
\hline $\begin{array}{l}\text { Geleceğe Dair } \\
\text { Umut Kaynağı ve } \\
\text { Neslin }\end{array}$ & $\begin{array}{l}\text { Fidan, Tohum, Meyve Bahçesi, Be- } \\
\text { reketli Toprak, Soyağacı Dall, Maya, } \\
\text { Kök }\end{array}$ & 7 & 11,7 & 9 & 14 & 3 & 12 & 12 & 13,5 \\
\hline Şefkat ve Sevgi & Can Yoldaşı, Güvenilir Dost, Soba, & & & & & & & & \\
\hline Dolu Olma & $\begin{array}{l}\text { Güneş, Sıcak Yuva, Tutunacak Dal, } \\
\text { Sevgi Çiçeği }\end{array}$ & 7 & 11,7 & 8 & 12,5 & 3 & 12 & 11 & 12,4 \\
\hline $\begin{array}{l}\text { Bakıma ve Korun- } \\
\text { maya Muhtaç } \\
\text { Olma }\end{array}$ & $\begin{array}{l}\text { Çiçek, Yavru, Fidan, Uçmayı Bilme- } \\
\text { yen Kuş, Bitki Fidesi, Gelincik }\end{array}$ & 6 & 10 & 6 & 9,4 & 3 & 12 & 9 & 10,1 \\
\hline $\begin{array}{l}\text { Zorlayıcı ve Yo- } \\
\text { rucu Olma }\end{array}$ & $\begin{array}{l}\text { Kaplumbağa, Şimşek Çakması, } \\
\text { Ağaçkakan, Kumar Makinesi, Gü- } \\
\text { rültü, Merdaneli Çamaşır Makinesi }\end{array}$ & 6 & 10 & 7 & 0,9 & - & - & 7 & 7,9 \\
\hline Eğitilebilir Olma & $\begin{array}{l}\text { Yazılmamış Kitap, İşlenmemiş Ma- } \\
\text { den, Papağan, Değerli Taş, Hamur }\end{array}$ & 5 & 8,3 & 5 & 7,8 & 2 & 8 & 7 & 7,9 \\
\hline Özgür Olma & Kuş, Gökyüzü, Akarsu, Kelebek & 4 & 6,7 & 4 & 6,3 & 1 & 4 & 5 & 5,6 \\
\hline $\begin{array}{l}\text { Sorgulayıcı, Keşfe- } \\
\text { dici Olma }\end{array}$ & Araştırmacı, Gazeteci, Gezgin & 3 & 5 & 2 & 3,1 & 1 & 4 & 3 & 3,4 \\
\hline Sorumsuz Olma & $\begin{array}{l}\text { Tüketici, Eğitilmemiş Hayvan, Bek- } \\
\text { lentisi Yüksek Müşteri }\end{array}$ & 3 & 5 & 2 & 3,1 & 1 & 4 & 3 & 3,4 \\
\hline Toplam & & 60 & 100 & 64 & 100 & 25 & 100 & 89 & 100 \\
\hline
\end{tabular}

* Kategorilerdeki katılimcilarm ve metaforlarm sayısı (n) ve yüzdesi (\%) rakamlar ile belirtilmektedir. Başat metafor imgeleri koyu renkli yazılmıştır.

Kategori 1: Hayat enerjisi ve mutluluk kaynağı olma: Bu kategori 17 katılımcı $(\% 19,1)$ ve 11 metafor $(\% 18,3)$ ile temsil edilmektedir. Bu kategoride başat metafor imgeleri olarak ifade edilebilecek iki metafor yer almaktadır. Bunlar bayram şekeri ve bahar mevsimi benzetmeleridir. Bu kategoriyi oluşturan metaforlarda çocukların insanlara neşe, enerji verdiği ve mutlu eden varlıklar olarak 
algılandığı vurgulanmaktadır. Bu metaforlarda ifade edilen bazı tanımlamalar şu şekilde yer almaktadır:

“... Bayram şekeri, çünkü çocuk bayram sabahı yediğimiz şeker gibi hayatımıza enerji ve ruhumuza neşe getirir... (E21).

“... Bahar Mevsimi, çünkü çocuk hayatın baharını yaşar ve o cıvıltı ile etrafındaki insanlara da baharı yaşatır... Yanındayken gençleşirsin" (E2).

“...Gökkuşağı, çünkü çocuk insanı kasvete sokan bir yağmurun arkasından çıkan gökkuşağı gibi hayata renk verir, canlılık katar... İnsana yeniden yaşamak için enerjisi verir" (E32).

Kategori 2: Masum ve menfaatsiz olma: Bu kategori 15 katılımc1 $(\% 16,9)$ ve 8 metafor $(\% 13,3)$ ile temsil edilmektedir. Bu kategoride başat metafor imgeleri olarak melek ve temiz kalp metaforları yer almaktadır. Bu kategoriyi oluşturan metaforlarda çocuğun masumiyeti ve iyi niyeti vurgulanmaktadır. Katılımc1ların ifade ettiği bazı metafor ve gerekçeleri şu şekilde yer almaktadır:

“...Melek, çünkü çocuğun günahı ve hesabı yoktur... Melek kadar masumdur..." (E63).

“ ...Temiz Kalp, çünkü kalbinde kötülüğe yer yoktur. Henüz kirlenmemiştir" (E11).

Kategori 3: Geleceğe dair umut kaynağı ve neslin devamını sağlayıcı olma: Bu kategori 12 katılımci $(\% 13,5)$ ve 7 metafor $(\% 11,7)$ ile temsil edilmektedir. $\mathrm{Bu}$ kategoride başat metafor imgeleri olarak fidan ve tohum metaforları yer almaktadır. Bu kategoriyi oluşturan metaforlarda çocuğun nesillerin aktarımı ve devamı için önemi ve ayrıca gelecek için umut algısı vurgulanmaktadır. Buna örnek olarak bazı metafor ve gerekçeleri şu şekilde yer almaktadır:

“...Tohum, çünkü insanın tohumu da çocuk... Çocuk olmayınca insanoğlunun nesli tükenir. Yok olur" (E51).

“...Maya, çünkü sen ne isen, çocuğunda aynı mayadan olduğu için aynı senin gibi, seni devam ettirir..." (E25).

Kategori 4: Şefkat ve sevgi dolu olma: Bu kategori 11 katılımc1 (\%12,4) ve 7 metafor $(\% 11,7)$ ile temsil edilmektedir. Bu kategoriyi oluşturan metaforlarda çocuğun şefkatli ve sevgi dolu olduğu algısı yer almaktadır. Buna örnek olarak bazı metafor ve gerekçeleri şu şekilde sıralanmaktadır: 
“Tutunacak dal, çünkü çocuk senin yere düşmene izin vermez. Tam da hayata yenildim dediğin anda tam yıkılıyorum dediğin zamanda şefkati ve sevgisi ile seni ayağa kaldırır" (E44).

“Güneş, çünkü gülümsemesi ile insanın içini 1sıtır. Öyle sevgi dolu bakar ki isinirsin..."(E13).

Kategori 5: Bakıma ve korunmaya muhtaç olma: Bu kategori 9 katılımc1 $(\% 10,1)$ ve 6 metafor (\% 10) ile temsil edilmektedir. Bu kategoride başat metafor imgeleri olarak çiçek ve fidan metaforları yer almaktadır. Bu kategoriyi oluşturan metaforların temel özelliği çocukların korunma, ilgi, destek ve bakıma muhtaçlığına dikkat çekilmektedir. Bazı örnek metafor ve gerekçeler şu şekilde sıralanmaktadır:

“Bitki Fidesi, çünkü çocuk bitki fidesi gibi narindir. Bakım ister. Eğer fideye bakmazsan büyüyemez serpilemez. Çocuğa da bitki fidesi gibi can suyunu vereceksin, koruyacaksın" (E1).

“Uçmayı Bilmeyen Kuş, çünkü kuş uçamazsa kurda kuşa yem olur. Çocuğu korumaz kollamazsan, iyi bakmaz sahip çıkmazsan kanadı kırılmış uçamayan kuşa döner" (E47).

Kategori 6: Zorlayıci ve yorucu olma: Bu kategori 17 katılımc1 $(\% 7,9)$ ve 6 metafor (\%10) ile temsil edilmektedir. Bu kategoriyi oluşturan metaforlarda çocuğun yorucu hatta zorlayıcı olduğu algısı yer almaktadır. Buna örnek olarak bazı metafor ve gerekçeler şu şekilde sıralanmaktadır:

“Kumar makinesi, çünkü kumar makinesi gibi sürekli para ya da zamanı harcar. Nasıl ki kumar makinesinde attığın para çoğu zaman boşa gider çocuk da öyle" (E7).

"Merdaneli çamaşır makinesi, çünkü dikkat etmezsen elini merdanenin arasına sıkıştırıp parçalayan makine gibi zarar verir. Çocuk şımarmaya müsait, fazla yüz verir isen kolunu kaptırırsın" (E82).

"Gürültü, çünkü çocuğun olduğu yerde sessizlik sakinlik yoktur. Başım kaldırmiyor" (E21).

Kategori 7: Eğitilebilir olma: Bu kategori 7 katılımc $(\% 7,9)$ ve metafor $(\% 8,3)$ ile temsil edilmektedir. Bu kategoriyi oluşturan metaforlarda çocuk yaşta verilen eğitimin geleceğini belirleyeceği ve kişisel gelişimi için eğitimin önemi 
vurgulanmaktadır. Buna örnek olarak bazı metafor ve gerekçeler şu şekilde yer almaktadir:

“Yazılmamış kitap, çünkü çocuk boş kitap sayfaları gibi yazı ile doldurulmayı bekler. Onu yetiştiren büyüten ne öğretirse, yani içine ne yazarsa onu yaşar..." (E2).

"İşlenmemiş maden, çünkü hayat işlenmemiş maden gibi çocuğu sana sunar ve nasıl değerlendirdiğine bakar. Bir haydut ya da topluma faydalı bir birey yaratabilirsin..." (E70).

Kategori 8: Özgür olma: Bu kategori 5 katılımc1 (\%5,6) ve 4 metafor $(\% 6,7)$ ile temsil edilmektedir. Bu kategoriyi oluşturan metaforlarda çocuğun toplum baskısından uzak, içinden geldiği gibi hareket edebildiği algısı şu şekilde vurgulanmaktadir:

"Kelebek, çünkü çocuk kelebek gibi özgürdür. Kelebek gibi naif ve özgürdür" (E89).

Kategori 9: Sorgulayıcı, keşfedici olma: Bu kategori 3 katılımcı $(\% 3,4)$ ve 3 metafor (\%5) ile temsil edilmektedir. Bu kategoride oluşan metaforlarda, çocuğun ezberci olmayan mantığı ile sorgulayan, meraklı, keşfedici özelliği algisı şu şekilde vurgulanmaktadır:

"Araştırmacı, çünkü her şeyi ama gördüğü her şeyi sorar ve sorgular" (E62).

"Gezgin, çünkü çocuk gezgin gibi yeni yerler keşfetmeyi, görmeyi ve gezmeyi sever. Bu yüzden çok da kaybolur ..." (E18).

Kategori 10: Sorumsuz olma: Bu kategori 3 katılımc1 $(\% 3,4)$ ve 3 metafor $(\% 5)$ ile temsil edilmektedir. Bu kategoride çocuğun herhangi bir sorumluluğu üstlenme durumunun olmaması ve kaygısız yaşaması şeklinde oluşan metafor algıları şu şekilde vurgulanmaktadır:

"Tüketici, çünkü hiçbir sorumluluğu ve hayat kaygısı yoktur. Yalnızca tüketmeye odaklıdır. Fatura kira derdi yoktur. Ekmek elden ..." (E43)

Çocuk metafor algılamnın torun sahibi olma değişkenine göre yordaması: Çocuk metaforu kategorilerinde katılımcıların torun sahibi olup-olmama değişkenine göre dağılımlarına bakıldığında iki grubun öncelik sıralamasında 
bazı farklılıklar olduğu görülmektedir (Tablo 4). Torun sahibi olan katılımc1ların hayat enerjisi, mutluluk kaynağı olma $(\% 18,8)$ metafor kategorisi ilk s1rada yer alırken, torun sahibi olmayanlarda (\%20) ikinci sırada yer almaktadır. Torun sahibi olan katılımcılarda ikinci sırada yer verilen masum ve menfaatsiz olma kategorisi (\%14) ise, torun sahibi olmayanlarda ( \%24) ilk sirada yer almaktadır. Torun sahibi olan ve olmayan her iki grubun da benzer şekilde üçüncü sırada geleceğe dair umut kaynağı ve neslin devamını sağlayıcı olma, dördüncü sırada şefkat ve sevgi dolu olma, beşinci sırada bakıma ve korunmaya muhtaç olma kategorilerine yer verdiği görülmektedir. Zorlayıcı ve yorucu olma kategorisi torun sahibi olan katılımclarda (\%10,9) altınc1 s1rada yer alırken torun sahibi olmayanlarda bu kategoride metafor yazan katılımc bulunmamaktadır. Eğitilebilir olma kategorisi torun sahibi olanlarda $(\% 7,8)$ yedinci sırada yer alırken, torun sahibi olmayanlarda $(\% 8)$ altınc1 s1rada, özgür olma kategorisi torun sahibi olanlarda $(\% 6,3)$ sekizinci, torun sahibi olmayanlarda (\%4) yedinci sırada yer almaktadır. Sorgulayıcı, keşfedici olma ve sorumsuz olma kategorileri ise, torun sahibi olanlarda $(\% 3,1)$ dokuzuncu, torun sahibi olmayanlarda (\%4) sekizinci sırada yer almaktadır.

\section{Tartışma}

$\mathrm{Bu}$ araştırma nesiller arası etkileşim kapsamında yaşlı yetişkinlerin "çocuk" kavramına ilişkin yaklaşımları ve metaforik algılarını ortaya çıkarmak amacı ile gerçekleştirilmiştir.

Yapılan bu araştırmanın sonucunda yaşlı yetişkinler kendi çocukluk deneyimlerini tanımlarken; keyifli ve mutlu, zorluklar ile mücadele, çocuk yaşta çalışma sorumluluğu üstlenme ve tüm olumsuz koşullara rağmen mutlu çocukluk dönemi şeklinde ifadelere yer vermiştir. Katılımclların tamamı çocuk ile iletişimi kolaylaştıran ya da engelleyen etkenlerin yaşlı yetişkin ve/veya çocuğa ait özellikler olduğunu ifade etmişlerdir. İletişim sırasında tarafların fiziksel ve davranışsal özelliklerinin kolaylaştırıcı ya da engelleyici olarak rol oynadığı belirlenmiştir. Ayrıca yaşlı yetişkinlerin çocuk ile ilgili olarak en fazla sayıda metaforun yer aldığı kategoriler sirasıyla; hayat enerjisi ve mutluluk kaynă̆ı olma, masum ve menfaatsiz olma, geleceğe dair umut kaynağı ve neslin devamin sağlayıcı olma, şefkat ve sevgi dolu olma, bakıma ve korunmaya muhtaç olma, zorlayıcı ve yorucu olma, eğitilebilir olma, özgür olma, sorgulayıc-keşfedici 
olma ve sorumsuz olma kategorilerinden oluşmaktadır. Aynı zamanda yaşlı yetişkinlerin torun sahibi olup-olmama değişkenine göre benzer ve farklı kavramsal kategorilerde metaforlara sahip oldukları belirlenmiştir.

Çalışmaya katılan yaşlı yetişkinlerin yarıya yakını (\%40) kendi çocukluğunu keyifli ve mutlu geçirdiğini, \% $\%$ 'i ise olumsuz şartlara maruz kalsa da çocukluğunu mutlu hatırladığını ifade etmiştir. Bu katılımcılara göre çocukluklarını mutlu hatırlamalarının sebebi ise o dönemlerini diledikleri gibi oyun oynayarak geçirebilmeleridir. İnsanlar yaşamın hangi döneminde olurlarsa olsunlar o dönemin özelliklerini yaşayabildikleri ölçüde doyuma ve mutluluğa ulaşabilirler. Çocukluk ve oyun birbiri ile bağlantılı iki kavramdır. Bu nedenle yaşlı yetişkinler de çocukluğu oyun oynama ile bağdaştırmış ve oyun oynayabildikleri ölçüde mutlu bir çocukluk yaşadıklarını ifade etmişlerdir. Çocukluk yılları deneyimi anne babayla kurulan ilişkiler, çocukluk dönemine ilişkin kişilik özelliklerini ve çocuklara bakış açısını etkileyebilen önemli bir unsur olabilmektedir (İçli, 2010). Bu nedenle çalışmaya katılan yaşlı bireylerin çocukluk çağı deneyimleri sorgulanmıştır.

Yaşlı yetişkinlere çocuklar ile iletişim kurabilme durumu ve iletişimi etkileyen unsurlar sorulduğunda katılımcıların tamamı çocuğun fiziksel ya da davranışsal özelliklerinin iletişim kurmada etkili olduğunu belirtirken, kendilerine ait özelliklerin çocukla iletişim kurmalarını etkilediğini düşünenlerin oranı \%74 olarak belirlenmiştir. Bu durumda yaşlı yetişkinlerin çocuk ile iletişim kurmak için çocuktan beklentilerinin olduğu görülmektedir.

Yaşlı yetişkinlerin torun sahibi olma değişkenine göre çocuk ile ilgili ifade ettikleri metaforlar incelendiğinde; çocuk ile ilgili olarak hem olumlu hem de olumsuz düşüncelere sahip oldukları görülmüştür. Yaşlı yetişkinlerin torun sahibi olma değişkenine göre çocuk kavramı metafor sıralamasında farklılıklar olmakla birlikte tanımlamaların çoğunlukla benzerlik gösterdiği görülmektedir. Katılımcıların çocuk metaforlarından en çok ifade ettikleri kavramın hayat enerjisi ve mutluluk kaynağı olma olduğu belirlenmiştir. Ancak torun sahibi olma değişkenine göre yaşlı yetişkinlerin çocuk metaforları karşlaştırıldığında, torun sahibi olan katılımcıların olumsuz tanımlamalara daha çok yer verdikleri belirlenmiştir. Yaşlı yetişkinlerde torun sahibi olma deneyimlerinin çocuk metaforlarında yer alan tanımlamaları ve öncelik sırasını etkilediği düşünülmektedir. Bununla birlikte olumlu ve olumsuz metafor sıralaması incelendiğinde olumsuz metaforların son sıralarda yer aldığı görülmektedir. 
Literatürde yaşlı yetişkinlerin çocuk ile ilgili düşüncelerine yer veren çok az çalışma yer almakla birlikte, araştırmalarda daha çok kuşaklararası dayanışma ya da çatışma konularına değinilmektedir (Altan ve Tarhan, 2018; Özmete, 2017; Canatan, 2016). Arpacı ve Şahin Tezel' in (2015) çalışmasında yaşlı yetişkinlerin çocuklar ile ilgili hem olumlu (torunlarının mutluluk, sevgi hissini vermesi) hem de olumsuz algılara (kuşak çatışması, maddiyat açıdan zorda bırakmaları, saygısızlık gibi) sahip olduğu vurgulanmıştır. Pesen'in (2015) 100 ebeveyn ile yaptığı çalışmada ise; farklı metaforlar elde edilmiş olup ebeveynlerin çocuk ile ilgili daha çok olumlu algilara sahip olduğu belirlenmiştir. Literatürde yer alan bilgilerin çok yüzeysel olduğu, olumlu ve olumsuz şeklinde kategorize edildiği görülmektedir. Yapılan bu çalışmanın geniş kapsamlı ve kavram analizleri üzerine yürütülmesinin literatüre daha detaylı ve aydınlatıcı bilgi katacağı düşünülmektedir.

\section{Sonuç ve Öneriler}

$\mathrm{Bu}$ araştırma sonuçları yaşlı yetişkinlerin kendi çocukluk deneyimlerini tanımlarken "keyifli ve mutlu, zorluklar ile mücadele, çocuk yaşta çalışma sorumluluğu üstlenme ve tüm olumsuz koşullara rağmen mutlu çocukluk dönemi şeklinde" ifadelere yer verdiğini ortaya koymaktadır. Katılımcıların kendi çocukluk deneyimleri çocuklara bakış açısını etkileyebilen bir unsur olması bakımından önem arz etmektedir. Yaşlı yetişkinlerin tamamının çocuk ile iletişimi kolaylaştıran ya da engelleyen etkenlerin yaşlı yetişkin ve/veya çocuğa ait özellikler olduğunu ifade ettiği, iletişim sırasında tarafların fiziksel ve davranışsal özelliklerinin kolaylaştırıcı ya da engelleyici olarak rol oynadığı belirlenmiştir. Ayrıca yaşlı yetişkinlerin torun sahibi olma değişkenine göre ifade ettikleri çocuk metaforları çok az farklılık teşkil etmekle birlikte genellikle benzer ve olumlu tanımlar şeklinde belirlenmiştir. Araştırmada çocuk kavramına yönelik metafor tanımlamalarında torun sahibi olan yaşlı yetişkinlerin torunu olmayan yaşlı yetişkinlere kıyasla daha olumsuz tanımlamalara yer verdikleri belirlenmiştir. Yaşlı yetişkinlerde torun sahibi olma deneyimlerinin çocuk metaforlarında yer alan tanımlamaları ve öncelik sırasını etkilediği düşünülmektedir.

Yaşlı yetişkinlerin yaşamları boyunca kendi varlıklarını ve yaşamı anlamlı kılmaları, sosyal açıdan çevresindeki insanlara öğretici ve örnek olmak hatta yararlı olabilmek şeklinde mümkün olmaktadır. Yaşlı yetişkinler, geçmiş ve 
gelecek arasında köprü görevini üstlenmekle birlikte, toplumun süreklilik bilincini sağlamaktadır. Nesiller arası dayanışma ve etkileşim hem yaşlı yetişkinlerin sosyal refahının hem de toplumların kendi refah ve varlıklarının sürdürülebilmesi açısından önem arz etmektedir. Nesiller arası etkileşim ve dayanışma, farklı kuşaklar arasındaki sosyal ilişkileri ifade etmektedir. Nesiller arası ilişkiler söz konusu olduğunda, yaşlılar ve çocuklar arasındaki etkileşim önemli bir eğitim ve sosyalizasyon ortamı olarak ortaya çıkmaktadır. Çocuk, genç ve yaşlı yetişkinler arasında bir bağ kurulmakta, yaşlılar toplumda aktif bir rol oynayabilmektedir. Ayrıca yaşlılar çocuk ve gençler arasındaki birçok toplumsal ve kültürel değerlerin oluşmasına yardımcı olmaktadır. Toplum kültürünün yeni kuşaklara aktarılması rolünü üstlenen yaşlılar, topluma katkı sağladıklarını, faydalı olduklarını düşünerek yaşamlarını anlamlı kılabilmektedir. Öte yandan toplumsal ve kültürel değerlerin yeni kuşaklara aktarımı ancak nesiller arası etkileşim yolu ile mümkün kılınmaktadır. Dolayısıyla, yaşlı yetişkinlere yönelik hizmetlerde gerek sosyal politikaların oluşumda gerekse yerel yönetimler ve sivil toplum örgütleri hizmet kapsamında yaşlı nüfusun ve çocukların birlikte zaman geçirebileceği faaliyetlerin düzenlemesi, nesiller arası etkileşimin devamlılı̆̆ında ve toplum refahında önem arz etmektedir. 


\title{
EXTENDED ABSTRACT \\ Metaphoric Perceptions and Approaches to the Concept of Children in Old Adults in the Scope of In- ter-Generation
}

\author{
* \\ Mehtap Pekesen- Demet Çelik-Ayşe Sonay Türkmen \\ Akdeniz University-Karamanoğlu Mehmet Bey University-Karamanoğlu Mehmet Bey University
}

Purpose: This research was carried out with the aim of revealing the approaches and metaphorical perceptions of individuals aged 50 and over (older adult/adult) regarding the concept of "child" within the scope of intergenerational interaction.

Materials and Methods: In the research, mixed research method, which is one of the mixed research methods in which quantitative and qualitative research methods are included, was used. The research was conducted with older adults aged 50 years or older. Research data were collected between October 1 and December 1, 2018 in Karaman City Center using introductory information and semi-structured interview forms created by the researchers $(n=100)$. In the metaphor section, the participants' "Child is like ... .; because ......" they were asked to complete the statement. SPSS 21 package program and content analysis technique were used in the analysis of the data. Metaphors that did not contain any metaphor images or that did not provide a valid justification for the metaphor (11 participants) were eliminated in line with expert opinion. 60 metaphors produced by 89 participants who were considered valid are listed in alphabetical order. In addition, Miles \& Huberman (1994) reliability formula (Reliability $=$ Consensus $/$ (Agreement + Disagreement) $)$ was used to create reliability in metaphor analysis and the agreement rate among the coders was determined as $85.7 \%$.

Results: The research findings consist of four parts. In the first part, the demographic/descriptive characteristics of the participants, in the second part, the childhood experiences of the participants, and in the third part, the factors affecting the communication of the older adults with the child. 
In the fourth chapter, the metaphors, categories and characteristics developed for the concept of "child" according to the variable of whether or not the elderly adults have grandchildren are defined. In addition, in this section, child metaphor predictions were made according to the variable of having grandchildren. According to the findings of the study, while older adults describe their childhood experiences; pleasant and happy, struggling with difficulties, taking responsibility for working at a young age, and happy childhood despite all negative conditions. All of the participants stated that the factors that facilitate or prevent communication with the child are the characteristics of the elderly adult and/or child. It has been determined that the physical and behavioral characteristics of the parties play a role as facilitator or hindrance during communication. In addition, according to their findings, the categories with the highest number of metaphors about the child are respectively; being a source of life energy and happiness, being innocent and selfless, being a source of hope for the future and ensuring the continuation of the generation, being full of compassion and love, being in need of care and protection, being compelling and tiring, being trainable, being free, being inquisitive-exploratory and consists of the categories of being irresponsible. At the same time, it was determined that older adults had metaphors in similar and different conceptual categories according to the variable of having grandchildren or not.

Conclusion: In the study, it was determined that negative definitions were included in the metaphors of the participants at lower rates. It has been determined that among older adults, those who have grandchildren use more negative definitions than older adults who do not have grandchildren. In the literature, in addition to positive definitions for the grandchildren of older adults, negative definitions are also reported in the elderly-child interaction (Arpacı \& Şahin, 2015). It is thought that the experiences of having grandchildren in older adults affect the definitions and priority order in child metaphors.

It is possible for older adults to make their own existence and life meaningful throughout their lives, by being a teacher, an example to the people around them, and even being useful. While older adults act as a bridge between the past and the future, they also provide the continuity awareness of the society. Intergenerational interaction and solidarity refers to 
social relations between two or more generations. When it comes to intergenerational relations, the interaction between the elderly and children emerges as an important educational and socialization environment. A bond is established between children, young and old adults, and the elderly can actively participate in society. In addition, it is ensured that many social and cultural values such as sharing, cooperation and solidarity for children and young people are experienced through the elderly. The elderly, who assume the role of transferring the culture of the society to the new generations, can make their lives meaningful by thinking that they contribute to the society and are useful. On the other hand, the transfer of social and cultural values to new generations is only possible through intergenerational interaction. Therefore, the organization of activities where the elderly population and children can spend time together is important in the continuity of intergenerational interaction, both in the formation of social policies in services for older adults and in the scope of services of local governments and non-governmental organizations.

\section{Kaynakça/Referances}

Aladağ, S. ve Kuzgun, M. (2015). Sınıf öğretmeni adaylarının 'değer' kavramına ilişkin metaforik algıları. Sakarya Üniversitesi Eğitim Fakültesi Dergisi, 29, 163-193.

Altan, S. ve Tarhan, S. (2018). Büyükanneden toruna: Yaşamboyu öğrenme sürecinde değer ve beceri aktarımı. Bartın Üniversitesi Eğitim Fakültesi Dergisi, 2(1), 26-42.

Arıkan, R. (2011). Araştırma yöntem ve teknikleri (1.Baskı). Ankara: Nobel Akademik Yayıncılık.

Arpacı, F. ve Şahin Tezel, F. (2015). Yaşlı bireylerin yaşlı ve çocuk etkileşimine ilişkin görüşleri. TSA, 19(1), 231-245.

Canatan, Ü. ve Boz, H. (2019). Hayat boyu öğrenme etkinliklerine katılımın aktif yaşlanmanin desteklenmesindeki rolü. Turkish Studies Social Sciences, 14(3), 343-363. doi:10.29228/TurkishStudies.225

Caring for children. 22 Temmuz 2019 tarihinde, https://www1.nyc.gov/site/dfta/caregivers/caring-for-children.page adresinden erişildi. 
Erdoğan, S. (2015). Hemşirelikte araştırma; süreç, uygulama ve kritik (2. Baskı). (Erdoğan, S., Nahcivan, N. ve Esin, M.S eds) İstanbul: Nobel Tip Kitabevi.

Goschler, J. (2007). Metaphors in cognitive and neurosciences which impact have metaphors on scientific theories and models? 28 Şubat 2021 tarihinde, http://www.metaphorik.de/sites/www.metaphorik.de/files/journalpdf/12_2007 goschler.pdf adresinden erişildi.

İçli, G. (2004). Huzurevinde kalan yaşlılar üzerine bir araştırma. Sosyoloji Araştırmaları Dergisi, 1, 5-24.

Horgan, M.A. and Fees, S.B. Undergraduate research community. 22 Temmuz 2019 tarihinde, http://www.kon.org/urc/horgan.html adresinden erişildi. Kasapoğlu, H. (2016). Öğretmen adaylarının Türk eğitim sistemine ilişkin algilarının metaforlar yoluyla analizi. Kuram ve Uygulamada Ĕ̆itim Yönetimi Dergisi, 22(1), 59-80.

Lakoff, G. (1992). The contemporary theory of metaphor. 28 şubat 2021 tarihinde, http:/comphacker.org/comp/engl338/files/2014/02/A9R913D.pdf adresinden erişildi.

Miles, M.B. and Huberman AM. (1994). Qualitative data analysis: An expanded sourcebook. (2 nd Edition).CA: Sage Publications.

Murphey, D., Cooper, M. and Moore, K.A. (2012). Children living with and cared for by grandparents: state-level data from the American Community Survey. Child Trends , 1-3.

Özmete, E. (2017). Türkiye'de kuşaklararası dayanışmanın değerlendirilmesi. Ankara: Ankara Üniversitesi Basımevi.

Statham, J. (2011). Grandparents providing child care. 22 Temmuz 2019 tarihindehttps://assets.publishing.service.gov.uk/government/uploads/system/uploads/attachment data/file/181364/CWRC-00083-2011.pdf adresinden erişildi.

Suwanrada, W., Sukontamarn, P. and Bangkaew, B. (2018). Who supports intergenerational redistribution policy? Evidence from old-age allowance system in Thailand. The Journal of the Economics of Ageing, 12, 24-34.

TÜİK. (2019). Adrese dayalı nüfus kayıt sistemi sonuçları. Sayı: 33705. 02 Mart 2021 tarihinde https://data.tuik.gov.tr/Bulten/Index?p=Adrese-DayaliNufus-Kayit-Sistemi-Sonuclari2019-33705 adresinden erişildi. 
Hacettepe Üniversitesi Geriatrik Bilim Merkezi. Yaşlılı̆̆ın sosyal boyutu. 22 Temmuz 2018 tarihinde, http://www.gebam.hacettepe.edu.tr/sosyal boyut/yasliligin sosyal boyutu.pdf adresinden erişildi.

Yıldırım, F. (2015). Çocukların dünyasına yaşlıları dahil etmek: “Okul temelli kuşaklararası dayanışma modelleri". Türkiye Sosyal Araştırmalar Dergisi, 19(1), 275-296.

Kaynakça Bilgisi / Citation Information

Pekesen, M., Çelik, D. ve Türkmen, A. S. (2021). Nesillerarası etkileşim kapsamında yaşlı yetişkinlerin çocuk kavramına ilişkin yaklaşımları ve metaforik algıları. OPUS-Uluslararası Toplum Araştırmaları Dergisi, 18(42), 5250-5275. DOI:10.26466//opus.908380. 